\title{
Mercury isotopes from the Pho Han Formation in Vietnam show no evidence for a volcanic trigger for the Devonian-Carboniferous boundary
}

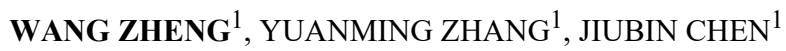 \\ AND SARAH CARMICHAEL ${ }^{2}$ \\ ${ }^{1}$ Tianjin University \\ ${ }^{2}$ Appalachian State University \\ Presenting Author: zhengw3@tju.edu.cn
}

Mercury and its stable isotopes are novel proxies of Earth's evolution and have been applied to infer large-scale volcanism, ocean redox conditions and their impacts on the evolution of life. Here we apply $\mathrm{Hg}$ concentrations and isotopes to investigate the possible trigger of the mass extinction at DevonianCarboniferous boundary (DCB, $359 \mathrm{Ma}$ ) and associated ocean anoxia (the Hangenberg Crisis), which represents one of the major Phanerozoic mass extinction events. It is thought to be associated with a variety of environmental crisis, including large scale volcanism, sea level change, continued expansion of terrestrial plants and increased topsoil development, changes in UV radiation, and ocean anoxia. However, its mechanism and expression are not globally unified and are still debated. We measured $\mathrm{Hg}$ concentration and isotope signals in the Pho Han Formation in northeastern Vietnam, which preserves the DCB in a sediment-starved basinal facies on the South China carbonate platform. We found elevated $\mathrm{Hg}$ content across the DCB, but no significant enrichment when normalized to total organic matter (TOC) or total sulfur (TS). Hg concentrations show much stronger correlation with TS rather than TOC. Moreover, elemental mapping by scanning electron microscope shows association of $\mathrm{Hg}$ with framboidal pyrite, suggesting that the elevated Hg across DCB was likely caused by ocean anoxia and enhanced scavenging of $\mathrm{Hg}$ by sulfide minerals. Furthermore, the mass independent fractionation of $\mathrm{Hg}$ isotopes (MIF) shows consistently positive signals across the entire Pho Han Formation with no systematic trend, which indicates that $\mathrm{Hg}$ was dominantly from atmospheric deposition with no major changes in the source of $\mathrm{Hg}$ across the DCB. Combined with previous studies on redox conditions, our new $\mathrm{Hg}$ isotope data argues against a global scale volcanism as the trigger of the Hangenberg Crisis and extinctions at the DCB, but instead suggests that enhanced ocean anoxia/euxinia as a result of increased bioproductivity was likely the major local trigger in the carbonate basins of South China. Therefore, the cause of the Hangenberg Crisis cannot be construed by $\mathrm{Hg}$ concentration alone, and local redox and paleoenvironmental conditions need to be examined in order to interpret the Hangenberg Crisis at different locations. 